\title{
Therapeutic effects of arthrocentesis in treatment of temporomandibular joint disorders
}

\author{
Malachovsky I, Statelova D, Stasko J, Mikuskova K, Smatanova M, Janickova M \\ Department of Stomatology and Maxillofacial Surgery, Jessenius Faculty of Medicine in Martin, Comenius \\ University in Bratislava, University Hospital in Martin, Slovakia. janickova@jfmed.uniba.sk
}

\section{ABSTRACT}

OBJECTIVE: Analyse, compare and evaluate the effects of the treatment arthrocentesis with a control group of non-steroid drugs treated patients.

MATERIAL AND METHODS: 1752 out-patients (1293 females, 459 males) were examined within the years 2013-2017. We evaluated the following criteria: gender, age, visual analog scale for pain (VAS), inter-incisal distance and reducing intake of orally administered analgesics.

RESULTS: The pain level of the group of patients with arthrocentesis had stabilized at mark 2.5 on the pain scale, unlike in the control group after treatment with non-steroidal anti-inflammatory drugs, pain had stabilized at mark 9 on the pain scale. The inter incisal distance amongst the first group was $37 \mathrm{~mm}$ and in the control group only $27 \mathrm{~mm}$, after completed treatment. The amount of applied analgesics in the group with arthrocentesis decreased to $100 \mathrm{mg}$ daily, while in the control group, the dose was adjusted to $700 \mathrm{mg}$ daily.

CONCLUSION: In the observed study, arthrocentesis was effective in reducing pain, amount of analgesics per day and improving the mobility of temporomandibular joint (TMJ). The results of this study we use in the ongoing project, that focuses on progressive and innovative methodology of endoscopically assisted arthrocentesis. (Tab. 4, Fig. 5, Ref. 39). Text in PDF www.elis.sk.

KEY WORDS: internal joint disorders, arthrocentesis, analgesics.

\section{Introduction}

The craniofacial area is one of the best innervated areas of the human body and the place where pains occur quite often - from ordinary headaches to unusual and difficult-to-explain pains such as trigeminal neuralgia. As the pains do not always arise from the joint itself, many authors believe that a wider term, such as craniomandibular disorders (23), should be introduced. Bell (3) proposed the term 'temporomandibular' disorders (TMD). This is a comprehensive term for a variety of clinical difficulties relating either to the muscles of the jaw, or the joint and associated structures, respectively both, i. e. muscles, joint and associated structures $(7,12,19,26,34)$.

Generally, pain or hypomobility of the TMJ due to disc dislocation, infectious, traumatic or metabolic arthritis or adhesions

Department of Stomatology and Maxillofacial Surgery, Jessenius Faculty of Medicine in Martin, Comenius University in Bratislava, University Hospital in Martin, Martin, Slovakia

Address for correspondence: M. Janíčková, MD, PhD, MPH, Department of Stomatology and Maxillofacial Surgery, Jessenius Faculty of Medicine in Martin, Comenius University in Bratislava, University Hospital in Martin, Kollarova 2, SK.036 59 Martin, Slovakia.

Phone: +421.43 .4203517$

Acknowledgement: The study is supported by a Grant of the Ministry of Health of the Slovak Republic 2018/14-UKMT-10 „Diagnostic and therapeutic effect of endoscopic assisted arthrocentesis to improve mandible mobility in internal temporomandibular joint disorders". is considered a good indication for arthrocentesis. Most often it appears to be used in patients with anterior disc dislocation without reposition. By means of arthrocentesis, a transient expansion of the joint space can be achieved; alternatively, it may produce decompression in an area of increased intra-articular pressure, for example during exudative inflammatory processes. By means of lavage pus and infectious agents of inflammation, metabolic wastes or products of degradation processes are washed out (5, $14,24,36)$. Arthrocentesis of the TMJ is frequently identified as a lavage of TMJ and is conventionally concluded without viewing the joint. The principal task of arthrocentesis is to release adhesions, to wash out with inflammatory mediators and besides, to affect directly with medical treatments $(6,20)$. The success of this method is attributed to the initial distension of the joint space, where it can disrupt intra-articular adhesions between the disc and the hole, and flush out the waste products of inflammation (7).

\section{Material and methods}

At the center for Temporomandibular Joint Diseases at the Department of Stomatology and maxillofacial surgery Jessenius Faculty of Medicine and University Hospital in Martin, 1752 out-patients (1293 females, 459 males) were examined within the years 2013-2017.

Among individual research tasks, intensity of pain was objectified by means of a visual analogue scale of pain before treatment and in monitored periods after treatment lasting three, six, and 


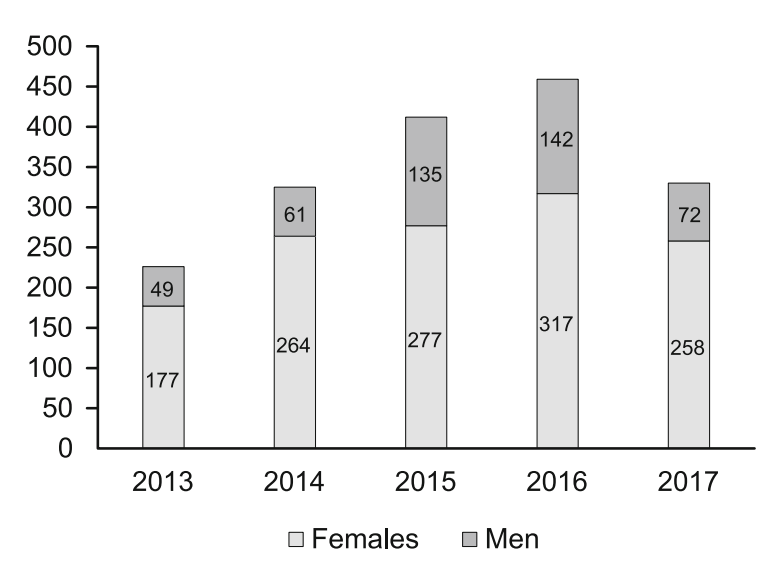

Fig. 1. Division of patients by year and sex.

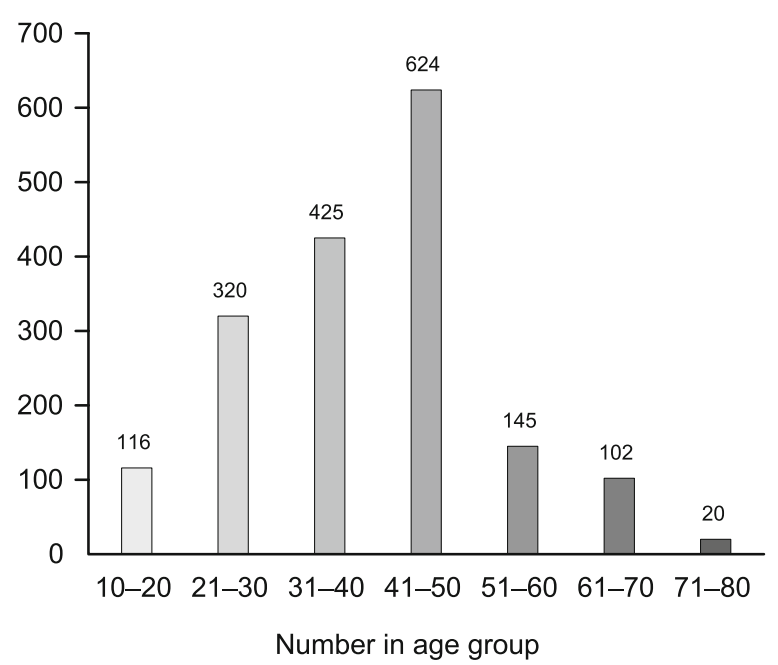

Fig. 2. Division of patients according to their age.

twelve months. Patients subjectively rated their pain on a scale numbered from 1 to 10 . In the monitored periods, the inter incisal distance between the upper and lower teeth in the frontal section was assessed. An important factor was also the consumption of analgesics during monitored periods.

Arthrocentesis of the TMJ was done in 419 patients (348 females, 71 males). In 233 cases, the right side and in 186 cases the left side were affected and subsequently treated.

The control group was composed of patients who were orally administered non-steroid anti-inflammatory drugs. Arthrocentesis was performed in an aseptic operating room. It was an in-office procedure and required only simple technical equipment (Figs 1 and 2).

With the patient's mouth open, an injection needle with a diameter of 1.0 to $1.2 \mathrm{~mm}$ was inserted into the posterior point of the upper joint space. The needle was obliquely and mediocranially inserted forward until the tip came into contact with the rear wall of the articular eminence. If there was inflammation of the joint, about $5 \mathrm{ml}$ of local anaesthetic was applied under slight pressure to achieve dilation of the joint. A second needle with the same diameter was then inserted into the marked anterior point.
The joint is flushed with at least $100 \mathrm{ml}$ of saline or Ringer's solution. Generally, the first needle serves as an inlet needle and the second one as a drain needle. Lavage is done very slowly via a syringe.

After lavage of the joint space, the anterior needle was taken out and the posterior needle served for application of the medical preparations. Removal of the needles was followed by mandible exercise in order to promote the disruption of adhesions. In the group of patients diagnosed for arthrocentesis and in control patients, the level of pain was tested by means of a visual analogue 10-level pain scale (VAS) and the length of treatment was followed (in months) (Fig. 3) during monitored periods of 3, 6 and 12 months.

\section{Results}

In the group of patients after arthrocentesis, there was significant pain relief. After three months of follow-ups the value was close to mark 1 on the pain scale. In the control patients after three months of follow-ups, the degree of pain stabilized at mark 4 on the pain scale. After six months of the monitored period, the degree of pain suffered by the group of patients with arthrocentesis had not changed, while with the control group of patients, there was a significant deterioration with pain rising to mark 8 on the pain scale. Twelve months after completed treatment, the pain level of the group of patients with arthrocentesis had stabilized at mark 2.5 on the pain scale. With the control patients, twelve months after treatment, their pain had stabilized at mark 9 and either other medicaments had to be applied or the daily dose of non-steroidal anti-inflammatory drugs had to be doubled (Fig. 3).

During the follow-up period in both groups of patients, the inter incisal distance between the upper and lower tooth sets in the frontal aspect was assessed.

Before treatment, in a group of patients with indicated arthrocentesis, this distance was about $27 \mathrm{~mm}$, and in the control group, approximately $26 \mathrm{~mm}$. Three months after completed treatment, these values did not significantly differ from each other and remained at $27 \mathrm{~mm}$, and $26 \mathrm{~mm}$ respectively. A significant change occurred six months into the monitored period, when in the group of patients with arthrocentesis, this value stabilized at $36 \mathrm{~mm}$, while in the control group of patients the distance was only 28 $\mathrm{mm}$. Twelve months after completed treatment, the inter incisal distance amongst the first group was $37 \mathrm{~mm}$ and in the control group only $27 \mathrm{~mm}$ (Fig. 4).

The fact that the application of targeted treatment for patients with arthrocentesis contributed to a significant reduction in the consumption of analgesics during treatment and after it is of key importance. The analgesics that the patients in both groups received daily were either Ibuprofen (400 mg) or Paracetamol (500 $\mathrm{mg}$ ). While in the group of patients treated with arthrocentesis had a daily analgesic intake before treatment of $800 \mathrm{mg}$ daily, the control patients had a daily intake of $850 \mathrm{mg}$.

After completed treatment and during the following three months, the amount of applied analgesics in the treatment group of patients decreased to $100 \mathrm{mg}$ daily, while in the control group of patients, the dose was adjusted to $700 \mathrm{mg}$ daily. 


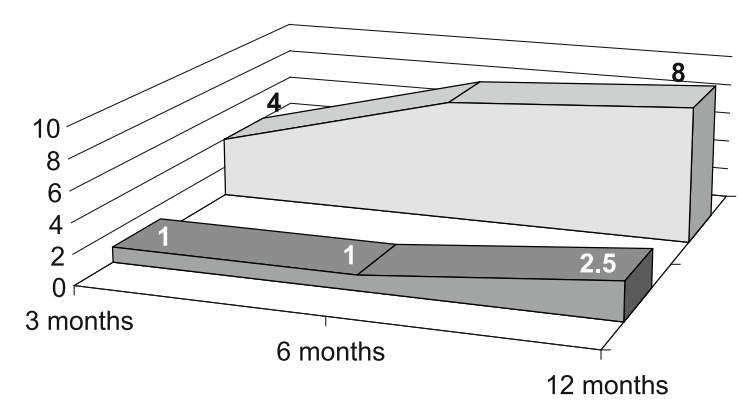

Arthrocentesis $\square$ Control group

Fig. 3. Determination of degree of pain (VAS) after treatment.

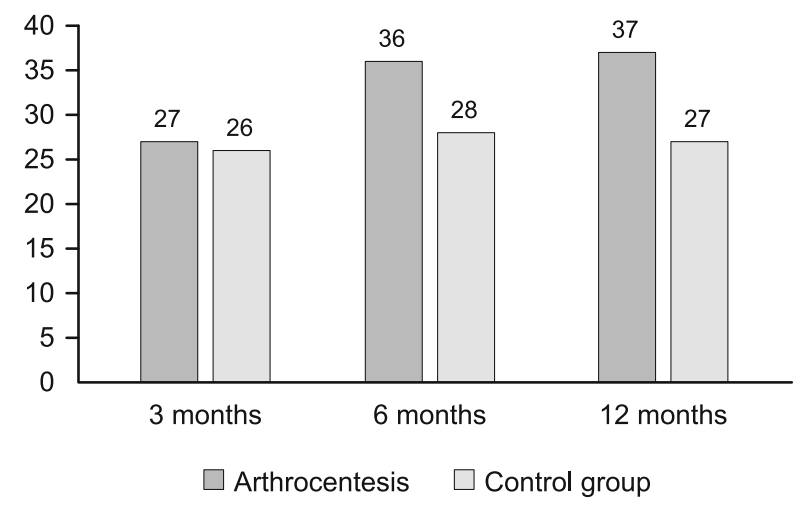

Fig. 4. Range of interincisal distance ( $\mathrm{mm})$.

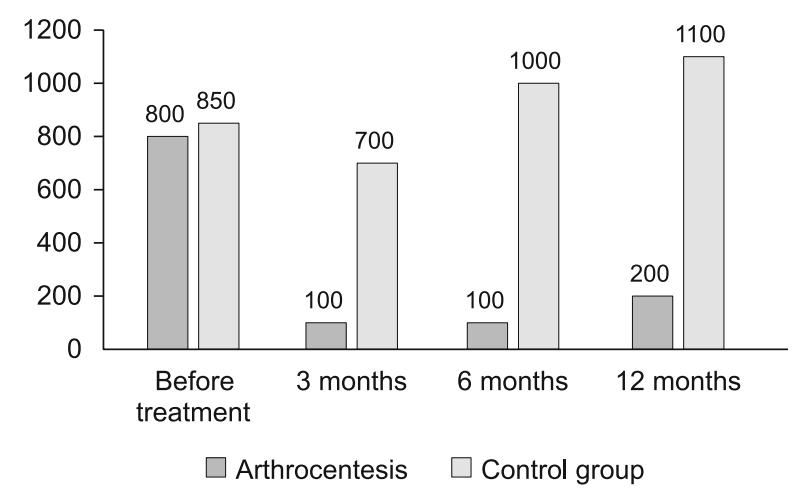

Fig. 5. Daily consumption of analgesics (mg).

During the six months following the end of treatment, in the treatment group of patients there was no change in increase of daily use of analgesics and this amount stabilised at a level of $100 \mathrm{mg}$. In the control group of patients, there was a rebound increase in daily consumption of analgesics, which reached $1000 \mathrm{mg}$.

Twelve months after completed treatment in the former group, the daily consumption of analgesics stabilized at $200 \mathrm{mg}$, whereas in the control group the daily consumption of analgesics increased to $1100 \mathrm{mg}$ (Fig. 5).

\section{Statistic assessment}

Below each chart of measured values, arithmetic means are given as indicators of position and standard deviations as indica- tors of variability. For each type of treatment, in table 1, p-values of the test of dissipation of variances (F-test) and correlation of mean values (Student's unpaired t-test) are listed. This test verifies a null hypothesis according to which the mean value of the treated group of patients is the same as the mean value of the control group. The test has two alternatives of counting of the test criterion and a p-value, which are determined by testing of dissipation values in both groups. Conformity of variances is tested by Fisher's F-test. The statistical significance of differences of mean values and variances of the variables are expressed in table 1 with a p-value of the t-test. p-values less than 0.05 indicate that studied mean values and variances are statistically significantly different (Tabs 1-4).

\section{Discussion}

A variety of intra-articular disorders respond well to arthrocentesis $(26,28)$. The success of this method is attributed to the initial distension of the joint space, where it can disrupt intra-articular

Tab. 1. Arthrocentesis - Control group.

\begin{tabular}{lcc}
\hline Variable & \multicolumn{2}{c}{$\mathrm{p}$} \\
\cline { 2 - 3 } & F-test & t-test \\
\hline vas & 0.0248 & 0.9253 \\
vas 3 & $<0.0001$ & $<0.0001$ \\
vas 6 & $<0.0001$ & $<0.0001$ \\
vas 12 & $<0.0001$ & $<0.0001$ \\
i-i & $<0.0001$ & $<0.0001$ \\
i-i 3 & $<0.0001$ & $<0.0001$ \\
i-i 6 & 0.0840 & $<0.0001$ \\
i-i 12 & $<0.0001$ & $<0.0001$ \\
sa & $<0.0001$ & $<0.0001$ \\
sa 3 & $<0.0001$ & $<0.0001$ \\
sa 6 & $<0.0001$ & $<0.0001$ \\
sa 12 & $<0.0001$ & $<0.0001$ \\
\hline vas - visual analogue scale (of pain), i-i - inter incisal distance, sa - consumption \\
of analgesics
\end{tabular}

Tab. 2. Arthrocentesis.

\begin{tabular}{ll}
\hline Variable & $\mathrm{p}$ \\
\hline vas & $<0.0001$ \\
vas 3-12 & $<0.0001$ \\
i-i & $<0.0001$ \\
i-i 3-12 & $<0.0001$ \\
sa & $<0.0001$ \\
sa 3-12 & $<0.0001$ \\
\hline
\end{tabular}

vas - visual analogue scale (of pain), i-i - inter incisal distance, sa - consumption of analgesics

Tab. 3. Control group.

\begin{tabular}{ll}
\hline Variable & $\mathrm{p}$ \\
\hline vas & $<0.0001$ \\
vas 3-12 & $<0.0001$ \\
i-i & $<0.0001$ \\
i-i 3-12 & $<0.0001$ \\
sa & $<0.0001$ \\
sa 3-12 & $<0.0001$ \\
\hline
\end{tabular}

vas - visual analogue scale (of pain), $\mathrm{i}-\mathrm{i}$ - inter incisal distance, sa - consumption of analgesics 
Tab. 4. Arithmetic means and standard deviations.

\begin{tabular}{|c|c|c|c|c|c|c|c|c|c|c|c|c|}
\hline Arthrocentesis & vas & $\begin{array}{c}\text { vas } \\
3\end{array}$ & $\begin{array}{c}\text { vas } \\
6\end{array}$ & $\begin{array}{c}\text { vas } \\
12\end{array}$ & $\mathrm{i}-\mathrm{i}$ & $\begin{array}{c}\mathrm{i}-\mathrm{i} \\
3\end{array}$ & $\begin{array}{c}i-i \\
6\end{array}$ & $\begin{array}{l}\mathrm{i}-\mathrm{i} \\
12\end{array}$ & $\mathrm{sa}$ & $\begin{array}{c}\mathrm{sa} \\
3\end{array}$ & $\begin{array}{c}\mathrm{sa} \\
6\end{array}$ & $\begin{array}{l}\text { sa } \\
12\end{array}$ \\
\hline Mean & 6.00 & 0.969 & 0.969 & 1.313 & 27.00 & 27.00 & 36.00 & 37.00 & 800 & 100 & 99.76 & 199.76 \\
\hline Deviation & 1.117 & 0.304 & 0.174 & 0.527 & 0.789 & 0.660 & 1.142 & 0.894 & 86.40 & 39.43 & 44.96 & 79.02 \\
\hline Control group & vas & $\begin{array}{c}\text { vas } \\
3\end{array}$ & $\begin{array}{c}\text { vas } \\
6\end{array}$ & $\begin{array}{c}\text { vas } \\
12\end{array}$ & $\mathrm{i}-\mathrm{i}$ & $\begin{array}{c}\mathrm{i}-\mathrm{i} \\
3\end{array}$ & $\begin{array}{c}i-i \\
6\end{array}$ & $\begin{array}{l}\mathrm{i}-\mathrm{i} \\
12\end{array}$ & $\mathrm{sa}$ & $\begin{array}{c}\mathrm{sa} \\
3\end{array}$ & $\begin{array}{c}\text { sa } \\
6\end{array}$ & $\begin{array}{l}\text { sa } \\
12\end{array}$ \\
\hline $\begin{array}{l}\text { Mean } \\
\text { Deviation }\end{array}$ & $\begin{array}{c}6.01 \\
0.927\end{array}$ & $\begin{array}{c}4.01 \\
0.785\end{array}$ & $\begin{array}{c}7.98 \\
0.765\end{array}$ & $\begin{array}{c}8.99 \\
0.362\end{array}$ & $\begin{array}{l}26.08 \\
1.447\end{array}$ & $\begin{array}{l}26.00 \\
1.279\end{array}$ & $\begin{array}{l}27.94 \\
1.301\end{array}$ & $\begin{array}{l}27.00 \\
1.206\end{array}$ & $\begin{array}{l}851.5 \\
47.38\end{array}$ & $\begin{array}{c}700 \\
72.13\end{array}$ & $\begin{array}{c}1000 \\
71.07\end{array}$ & $\begin{array}{c}1101 \\
138.17\end{array}$ \\
\hline
\end{tabular}

vas - visual analogue scale (of pain), i-i - inter incisal distance, sa - consumption of analgesics

adhesions between the disc and the hole, and flush out the waste products of inflammation $(2,5,7,12)$.

Frost and Kendell reported that arthrocentesis can be considered as a treatment choice between non-surgical treatment and arthroscopic surgery. Goudot et al studied comparatively about formation of pain and function after arthroscopy and arthrocentesis of the TMJ and reported that both arthroscopy and lavage are beneficial methods for function progress and decrease of pain (1, $8,17)$. In the studies, it has been reported up to $91 \%$ effective rate belonging to arthrocentesis to treat patients with anterior disc displacement without reduction (16). To determine the indication of case is important, because arthrocentesis can be inefficient in the patients who has bony changes, fibroankylosis and perforation of the disc (37). Treatment with arthrocentesis is very effective and the results are comparable to arthroscopy or arthrotomy. The success of arthrocentesis is indicated in 70-80\% of cases, which is comparable to arthroscopy (more than an $80 \%$ success rate) $(9,11,15,25,27)$.

Today, arthrocentesis of the temporomandibular joint is used not only in cases of acute closed lock but also in the treatment of various temporomandibular disorders. Thus, the most frequent indication is an acute anterior displacement of the articular disc without reduction or hypomobility of the joint with occurrences of disc adhesions (a stuck disc). It is possible to select arthrocentesis as a palliative procedure for patients with an acute episode of degenerative or rheumatoid arthritis and also for patients with a painful displacement of the disc with reduction, which rarely responds to conservative treatment. Treatment success is prominent in cases of acute patients or patients with a history of short-term problems $(4,30,32)$.

Opinions on the amount of solution used for lavage of the joint space are not uniform, but it was discovered that for therapeutic lavage during arthrocentesis to be effective in washing away most undesirable substances from the joint space, at least $100 \mathrm{ml}$ of solution should be used. Generally, it is recommended to use $200 \mathrm{ml}$ of solution $(25,26,34)$.

Exercise and treatment of the TMJ with arthrocentesis significantly contribute to improving the mobility of intra-articular adhesions. Some authors recommend performing these activities during arthrocentesis. We prefer the patient at rest during arthrocentesis and manipulation and mobilization exercises are carried out after removing the needles. It is assumed that the movement of the needles during exercise might cause traumatization of joint heads. Some authors consider diagnostic or therapeutic intra-capsular injection as a variant of arthrocentesis $(13,26,31$, 33). They fill the joint space with a solution injected with just one single needle and thereby temporarily extend the joint space. This procedure is effective in cases of dislocation of the joint disc or adhesions (10, 21, 36, 38, 39).

\section{Conclusion}

The results of this study we use in the ongoing project that focuses on progressive and innovative methodology of endoscopically assisted arthrocentesis. The main idea is to use and combine the advantages of arthrocentesis and arthroscopy. The innovative nature of the project lies in the use of a single cannula during the arthrocentesis to introduce a $0.8 \mathrm{~mm}$ thick optical fiber into the intra-articular space, allowing visualization, diagnosis of the degree of tissue damage and subsequent treatment. After removing of the optical device, we aspirate and then inject the saline solution with the same cannula in a total dose of $100 \mathrm{ml}$. The total duration of the procedure will be from 20 to 40 minutes, depending on the patient's cooperation and the range of damage inner structures or adhesion of joint tissues.

The procedure can be performed in local anesthesia, as compared to arthroscopy, this leads to elimination of health risks of general anesthesia, costs associated with pre-operative examinations and hospitalization. At the same time, we anticipate benefits in patient management, reducing treatment times and patient sick leave, reducing analgesics consumption.

\section{References}

1. Al-Belasy FA, Dolwick MF. Arthrocentesis for the treatment of temporomandibular joint closed lock: a review article. Int J Oral Maxillofac Surg 2007; 36: 773-782.

2. Al-Delayme RMA et al. The efficacy of plateles rich plasma injection in the superior joint space of the temporomandibular joint guided by ultrasound in patient with non-reducing disk displacement. J Maxilofac Oral Surg 2017; 16: 43-47.

3. Bell WE. Clinical management of temporomandibular disorders. Chicago: Year Book Medical, 1982.

4. Bhargava D, Jain M, Deshpande A, Singh A, Jaiswal J. Temporomandibular joint arthrocentesis for internal derangement with disc displacement without reduction. J Maxillofac Oral Surg 2015; 14 (2): 454-459.

5. Campos PSF et al. Temporomandibular joint adhesion without mouthopening limitation. J Oral MaxilofacSurg 2008; 66 (3): 551-554. 
6. Dimitroulis G. Temporomandibular disorders: a clinical update. Brit Med J 1998; 317: 190-194.

7. Fazal M et al. Effect of arthrocentesis in treatment of temporomandibular joint disorders: a doubleblind, randomised controlled trial. Pakistan Oral Dental J 2017; 30: 205.

8. Frost DE, Kendell BD. Part II: the use of arthrocentesis for treatment of temporomandibular joint disorders. J Oral Maxillofac Surg 1999; 57: $583-587$.

9. Gorrela $\mathbf{H}$ et al. Efficacy of temporomandibular joint arthrocentesis with sodium hyaluronate in the management of temporomandibular joint disorders: A prospective randomised control trial. J Maxilofac Oral Surg 2017; 16: 479-484.

10. Griffitts TM et al. Walker repair of the temporomandibular joint: a retrospective evaluation of 117 patients. J Oral Maxilofac Surg 2007; 65 (10): 1958-1963.

11. Gurung T et al. Efficacy of arthrocentesis versus arthrocentesis with sodium hyaluronic acid in temporomandibular joint osteoarthritis: A comparison. National J MaxilofacSurg 2017; 8 (1): 41.

12. Halmova K, Holly D, Stanko P The influence of cranio-cervical rehabilitation in patients with myofascial temporomandibular pain disorders. Bratisl Med J 2017; 118 (11): 710-713.

13. Hamada $\mathrm{Y}$ et al. Cytokine and clinical predictors for treatment autcome of visually guided temporomandibular joint irrigation in patients with chronic closed lock. J Oral MaxilofacSurg 2008; 66 (1): 29-35.

14. Ishimaru JI, Ogi $\mathbf{N}$ et al. Effects of a single arthrocentesis and a COX2 inhibitor on disorders of temporomandibular joints. A preliminary clinical study. Br. J Oral MaxillofacSurg 2003; 41: 323.

15. Kaneyama K, Segami $\mathbf{N}$ et al. Prognostic factors in arthrocentesis of the temporomandibular joint: Comparison of bradykinin, leukotriene B4, prostaglandin E2 and substance P level in synovial fluid between successful and unseccessful cases. J Oral MaxillofacSurg 2007; 65: 242-247.

16. Kaneyama K, Segami $\mathbf{N}$ et al. The ideal lavage volume for removing bradykinin, interleukin- 6 and protein from the temporomandibular joint by arthrocentesis. J Oral MaxillofacSurg 2004; 62: 657.

17. Kemal M. The effect of arthrocentesis in temporomandibular joint internal derangement with magnetic resonance imaging. International Journal of Applied Dental Sciences 2017; 3 (4): 148-151.

18. Koniarova A, Sedlata Juraskova E, Spidlen M, Statelova D. The influence of orthodontic non-extraction treatment on the change in the inclinacion and position of incisors in the Europoid race. Bratisl Med J 2017; 118 (11): 662-668.

19. Kurita $\mathbf{H}$ et al. Comparison of imaging follow-up between joints with arthroscopic surgery (lysis and lavage) and those with nonsurgical treatment. J Oral Maxilofac Surg 2007; 65 (7): 1309-1315.

20. Li C, Long $X$ et al. Osteoarthritis changes after superior and inferior joint space injection of hyaluronic acid for the treatment of temporomandibular joint osteoarthritis with anterior disc displacement with outreduction: A cone beam computed tomographic evaluation. J Oral Maxilofac Surg 2015; 73: 232-244.

21. Malachovský I, Statelová D. Artrocentéza TMK. Stomatológ 2001; 11 (3): $22-23$.

22. Malachovský I, Statelová D. Diagnostika a liečba porúch temporomandibulárneho kíbu. Martin: Libuša Chrasteková vydavatel'stvo, 2011.
23. McNeill CH, Danzing WM et al. Craniomandibular (TMJ) disordersThe state of the art. J Prosth Dentistry 1980; 44 (4): 434-437.

24. Melo M, DeB et al. Influence of arthrocentesis irrigation volume at temporomandibular disorder treatment. Indian J Dent Res 2017; 28 (6): 655.

25. Mračna J. Distribution, clinical manifestations and diagnosis of temporomandibular disorders. Bratisl Med J 1992; 93 (10): 550.

26. Nishimura M, Segami $\mathbf{N}$ et al. Comparison of cytokine level in synovial fluid between successful and unseccessful cases in arthrocentesis of the temporomandibular joint. J Oral Maxillofac Surg 2004; 62: 284.

27. Nishimura M, Segami N et al. Prognostic factor in arthrocentesis of the temporomandibular joint: Evaluationof 100 patients with internal derangement. J Oral Maxillofac Surg 2001; 59: 874.

28. Nishimura M, Segami $\mathbf{N}$ et al. Relationships between pain-related mediators and both synovitis and joint pain in patients with internal derangements and osteoarthritis of the temporomandibular joint. Oral Surg Oral Med Oral Pathol Oral Radiol Endod 2002; 94: 328.

29. Nitzan DW, Dolwick FM, Heft MW. Arthroscopic lysis and lavage of the temporomandibular joint. J Oral Maxillofac Surg 1990; 48 (8): 796-801.

30. Nitzan DW, Dolwick FM, Martinez GA. Temporomandibular joint arthrocentesis. J Oral Maxillofac Surg 1991; 49: 1163-1172.

31. Nitzan DW, Haaman HL. Arthrocentesis: A minimaly invasive approach to the temporomandibular joint. Minimaly invasive oral and maxilofacial surgery. Springer-Verlag GmbH Germany 2018: 45-73.

32. Sato $\mathbf{S}$ et al. Effect of lavage with injection of sodium hyaluronate for patients with nonreducing disc displacement of the temporomandibular joint. Oral Surg Oral Med Oral Pathol Oral Radiol Endod 1997; 84 (3): 241-244.

33. Sato $S$ et al. Evaluation of mouth opening exercises after pumping of the temporomandibular joint in patients with nonreducing disc displacement. J Oral Maxilofac Surg 2008; 66 (3): 436-440.

34. Sequeira $\mathbf{J}$ et al. Efficacy of sodium hyaluronate for temporomandibular joint disorder by single - puncture arthrocentesis. J Maxilofac Oral Surg 2018. doi.org/10.1007/s12663-018-1093-4.

35. Tanaka $\mathbf{E}$ et al. Modeling of the effect of friction in the temporomandibular joint on displacement of its disc during prolonged clenching. J. Oral Maxilofac Surg 2008; 66 (3): 462-468.

36. Tvrdy P, Heinz P, Pink R. Arthrocentesis of the temporomandibular joint: A review. Biomed Pap Med Fac Univ Palacky Olomouc 2015; 159: 31-34.

37. Yura S, Totsuka Y, Yoshikawa T, Inoue N. Can arthrocentesis release intracapsular adhesions? Arthroscopic findings before and after irrigation under sufficient hydraulic pressure. J Oral Maxillofac Surg 2003; 61: $1253-1256$.

38. Zemen J, Krňoulová J. Příspěvek ke klasifikaci poruch temporomandibulárního kloubu. Prakt zub Lék 1997; 45 (3): 27-30.

39. Zhang SY, Yang $\mathrm{CH}$ et al. Plain film artrography applied to the diagnosis of intra-articular adhesions of the temporomandibular joint. J Oral Maxillofac Surg 2007; 65: 212-217.

Received November 2, 2018. Accepted January 18, 2019. 